\title{
Tecoma em uma égua
}

\author{
Thecoma in a mare
}

\section{Fernanda Silveira Nóbrega ${ }^{1}$, Giordano Cabral Gianotti ${ }^{1}$, Carlos Afonso de Castro Beck ${ }^{2}$, Marcelo Meller Alievi $^{2}$, Alice Gomes ${ }^{3}$, Natália Schmidt Arruda ${ }^{3}$, Talita Franzen Rocio ${ }^{3}$, Paula Cristina Gonzalez ${ }^{3}$ \& Márcio Poletto Ferreira}

\begin{abstract}
RESUMO
Grandes prejuízos na reprodução eqüina podem ser causados por afecções ovarianas, dentre elas, podemos citar: hematomas, abscessos e torções de ovário, distúrbios neoplasicos, como os tumores de células germinativas, tumores mesenquimatosos, tumores das células da granulosa e tumores de células da teca (tecoma) sendo que, entre estes, o tecoma é considerado raro. Os tecomas são hormonalmente ativos causando alterações no comportamento e no ciclo estral das éguas. Por ser de apresentação rara, os detalhes da clínica, ultrassonografia, endocrinologia e histologia desse tumor não são descritos na literatura veterinária. $O$ presente trabalho descreve o caso de uma égua submetida a ovariectomia unilateral para remoção de um tumor no ovário esquerdo que no exame histopatológico foi caracterizado como tecoma. O procedimento e a evolução do caso foram satisfatórios e o animal recebeu alta após a retirada dos pontos de pele em 15 dias. Decorrido um ano da cirurgia, o animal encontra-se com ovário direito funcional e ciclando o que demonstra êxito no tratamento adotado.
\end{abstract}

Descritores: Ovariectomia, Tumor Ovariano, Ovário

\begin{abstract}
The ovarian pathologies reduce the reproductive performance. The most common ovarian pathologies are hematoma, abscess, torsion and neoplasm, such as germinative cells tumors, mesenquimatous tumors, granulosa cell tumors and theca cell tumors. The last one is denominated thecoma and ist considered a rare neoplasm. These tumors produce hormones, causing changes in the mare's attitude and in the estral cycle. Due to its rarity, the details of its clinical presentation, ultrasound, endocrinology and histology are not described in veterinary literature. The present paper reports the case of a mare, which was submitted to unilateral ovariectomy in order to remove the affected (left) ovary and the tumor. The surgery and the evolution of the patient were satisfactory. The animal was discharged fifteen days after the surgery as the stitches were already taken. One year after the surgery the mare has follicular activity and accepts mating. Therefore we concluded that the treatment choused was successful.
\end{abstract}

Keywords: Ovariectomy, Ovarian Tumor, Ovarian. 


\section{INTRODUÇÃO}

As mudanças de comportamento em éguas com tumor ovariano estão relacionadas à produção excessiva de hormônios pelo ovário atingido pela neoplasia. Muitas vezes, o aumento na secreção de testosterona acaba promovendo o comportamento masculinizado, agressivo e a persistência da égua em anestro $[1,11]$. O tratamento de eleição para os tumores ovarianos é a exérese cirúrgica [8].

Diferentes técnicas e acessos cirúrgicos podem ser utilizados para realização de ovariectomia unilateral. Dentre esses, pode-se citar a laparotomia com acesso pelo flanco com o animal em estação ou em decúbito, a laparotomia mediana ventral, a laparotomia com acesso para-inguinal oblíquo e, mais recentemente, a laparoscopia com o animal em estação ou decúbito dorsal [4].

O tecoma é um tumor do estroma ovariano funcionante, de caráter benigno, derivado dos cordões sexuais da gônada embrionária que originam as células da granulosa e da teca. Tem aspecto fasciculado semelhante ao fibroma, porém, com coloração amarelada, devido à presença de células produtoras de hormônios. Microscopicamente, as células são fusiformes, semelhantes a fibroblastos, porém, contém citoplasma claro e rico em lipídeos [10]. Os tecomas são de apresentação incomum em eqüinos [8].

O objetivo deste trabalho é relatar o caso de uma égua com tumor ovariano submetida à ovariectomia unilateral esquerda e posterior identificação de tecoma por meio de exame histopatológico.

\section{RELATO DE CASO}

Uma égua crioula de doze anos de idade foi encaminhada ao Hospital de Clínicas Veterinárias da UFRGS (HCV-UFRGS) com histórico de anestro de dois anos. Ao exame físico, constatou-se presença de pêlos longos na região da cabeça (Figura 1), engrossamento do pescoço, temperamento agressivo e desinteresse por machos, aspectos que, acrescidos de história de prenhez anterior, foram relatadas pelo proprietário na anamnese. $\mathrm{O}$ exame clínico incluiu palpação retal, onde se constatou assimetria entre os ovários, estando o esquerdo com aproximadamente seis centímetros, consistência firme e ausência de folículos, e o ovário direito com aproximadamente três centímetros. Essa assimetria foi confirmada por meio de exame ultrassonográfico transretal. Na dosagem sérica hormonal constatou-se aumento na concentração de testosterona (18ng/dL), estando a progesterona dentro dos limites fisiológicos para a espécie.

O resultado do exame clínico e os dados laboratoriais foram sugestivos de neoplasia ovariana, sendo, então, o animal encaminhado à cirurgia para biópsia excisional do ovário esquerdo. $\mathrm{O}$ animal foi submetido à anestesia geral inalatória, sendo posicionado em decúbito lateral direito. Após tricotomia, a anti-sepsia do flanco esquerdo foi feita incisão de pele de aproximadamente $15 \mathrm{~cm}$, no centro da fossa paralombar esquerda, divulsionando em seguida as camadas musculares até se acessar a cavidade abdominal.

Para facilitar a visualização e exteriorização do ovário esquerdo, um auxiliar realizou palpação retal para localização e direcionamento do ovário até o local da abertura abdominal (Figura 2). Após identificação e debridamento das estruturas adjacentes ao pedículo ovariano, este foi transfixado por meio de duas ligaduras transfixantes com a utilização de fio categute cromado ${ }^{1} n^{0} 2$, sendo na sequiência seccionado próximo ao ovário. $\mathrm{O}$ fechamento da cavidade abdominal foi realizado em quatro planos, utilizando fio poliglactina ${ }^{2} 910 \mathrm{n}^{\circ} 3$ com pontos de Sultan para síntese do peritônio e musculatura. Para a redução de espaço morto e síntese de pele, a rafia foi feita com pontos isolados simples, utilizando fio mononáilon $^{3} \mathrm{n}^{\mathrm{o}} 0$.

A análise histopatológica do ovário evidenciou a presença de cistos associada com a proliferação de células fusiformes arranjadas em redemoinho com hemossiderose, sendo compatível com tecoma (Figura 3 A e B).

$\mathrm{O}$ animal apresentou-se bem durante todo o período pós-operatório, recebendo alta hospitalar no décimo dia. Um ano após o procedimento cirúrgico o animal encontra-se com o ovário direito funcional e está ciclando normalmente.

\section{DISCUSSÃO}

Para a realização de laparotomias através do acesso pelo flanco com animais em estação, além de uma boa sedação e bloqueio anestésico local, o temperamento do animal é fator decisivo para determinar a opção pela técnica [5]. O temperamento da égua do relato inviabilizou a realização do procedimento 
Nóbrega F.S., Gianotti G.C., Beck C.A.C., Alievi M.M.,Alice G., Arruda N.S., Rocio T.F., Gonzalez P.C. \& Ferreira M.P. Tecoma em uma égua. Acta Scientiae Veterinariae. 36(2): 185-189.

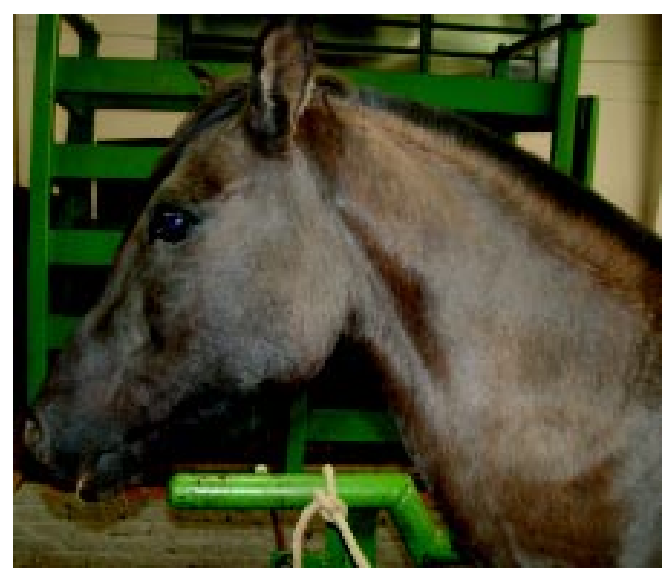

Figura 1. Presença de pêlos longos na região da cabeça.

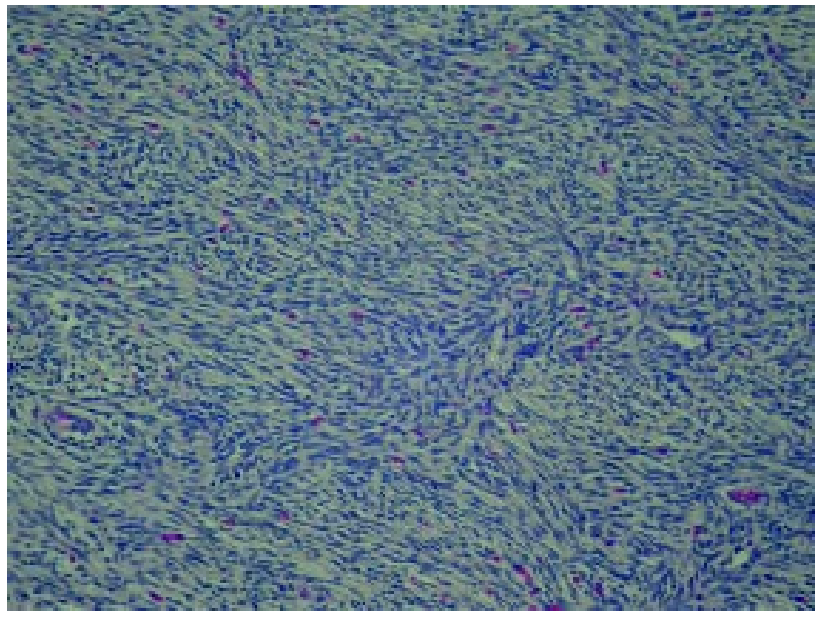

Figura 3 A. Presença de áreas de redemoinho com crescimento desordenado de células. Aumento de $20 \mathrm{X}$.

com o eqüino em estação, uma vez que o animal era bastante agressivo e inquieto para manipulação.

$\mathrm{O}$ acesso pela linha média ventral é mais utilizado em tumores grandes, ou para ovariectomia bilateral eletiva [3], é feito com o animal em decúbito dorsal, o que pode dificultar a completa exteriorização do ovário para ligadura dos vasos [3,5]. No presente relato, por se tratar de uma ovariectomia unilateral, optou-se pelo acesso pelo flanco, o que facilitou a localização do ovário além de permitir um pós-operatório com uma incisão de menor tamanho e menor tensão quando comparada à incisão ventral.

As complicações abdominais mais comuns decorrentes deste tipo de procedimento cirúrgico são: hemorragia no pedículo ovariano ou parede, dores abdominais, seroma ou hematoma, infecção e deiscência dos pontos na linha de incisão e peritonite, sendo independentes da técnica utilizada [6]. No caso relatado, o animal apresentou deiscência de quatro

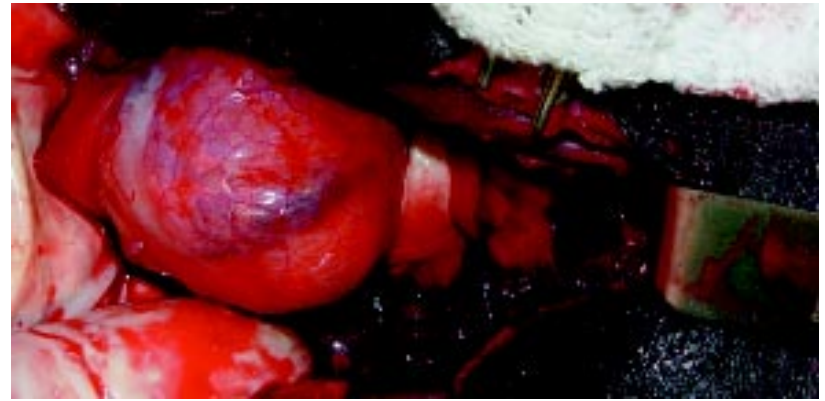

Figura 2. Exposição do ovário direito através da abertura da cavidade abdominal.

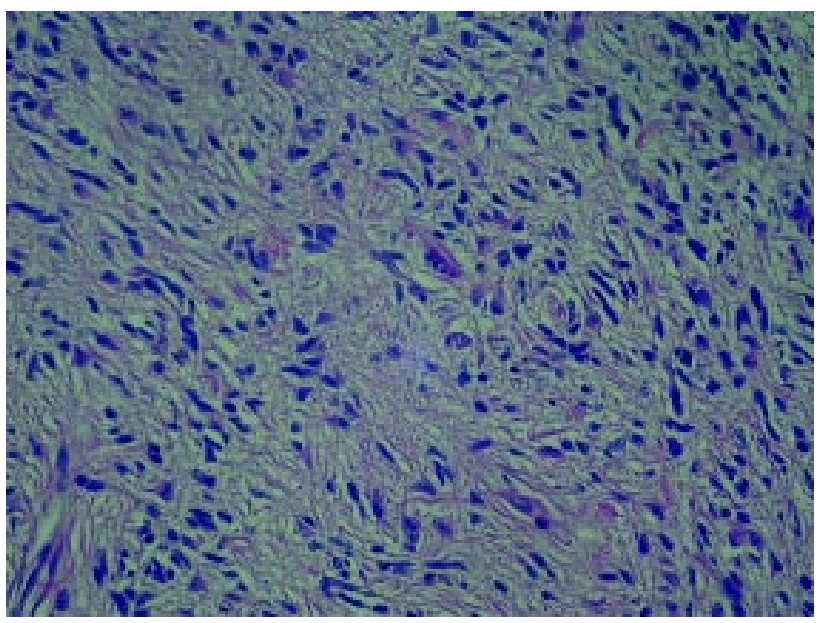

Figura 3 B. Presença de citoplasma claro (seta preta) e células fusiformes (seta branca). Aumento de 40X

pontos de pele. Foi feita limpeza diária com solução fisiológica estéril, tratando-se a mesma como ferida aberta.

Há uma grande variedade de causas para o aumento no tamanho dos ovários em éguas, incluindo causas neoplásicas e não-neoplásicas [7]. Entre as causas não-neoplásicas, estão os hematomas e abscessos ovarianos e as torções de ovário [9]. Dentre as causas neoplásicas, o tecoma é a mais rara [8]. No caso relatado, o exame histopatológico do ovário esquerdo evidenciou características que levaram ao diagnóstico de tecoma.

O tecoma tem capacidade de produzir hormônios esteróides que, em níveis elevados, podem ser detectados na dosagem hormonal sérica [2]. Nos casos de tecoma descritos, a maioria não indica aumento na dosagem sérica de progesterona. A produção de hormônios por este tumor está associada com mudanças no comportamento [8]. No caso descrito, a égua apresentava nível de testosterona aumentado - 18ng/dL, (valor fisiológico esperado de <10ng/dl), níveis de progesterona dentro dos valores fisiológicos 


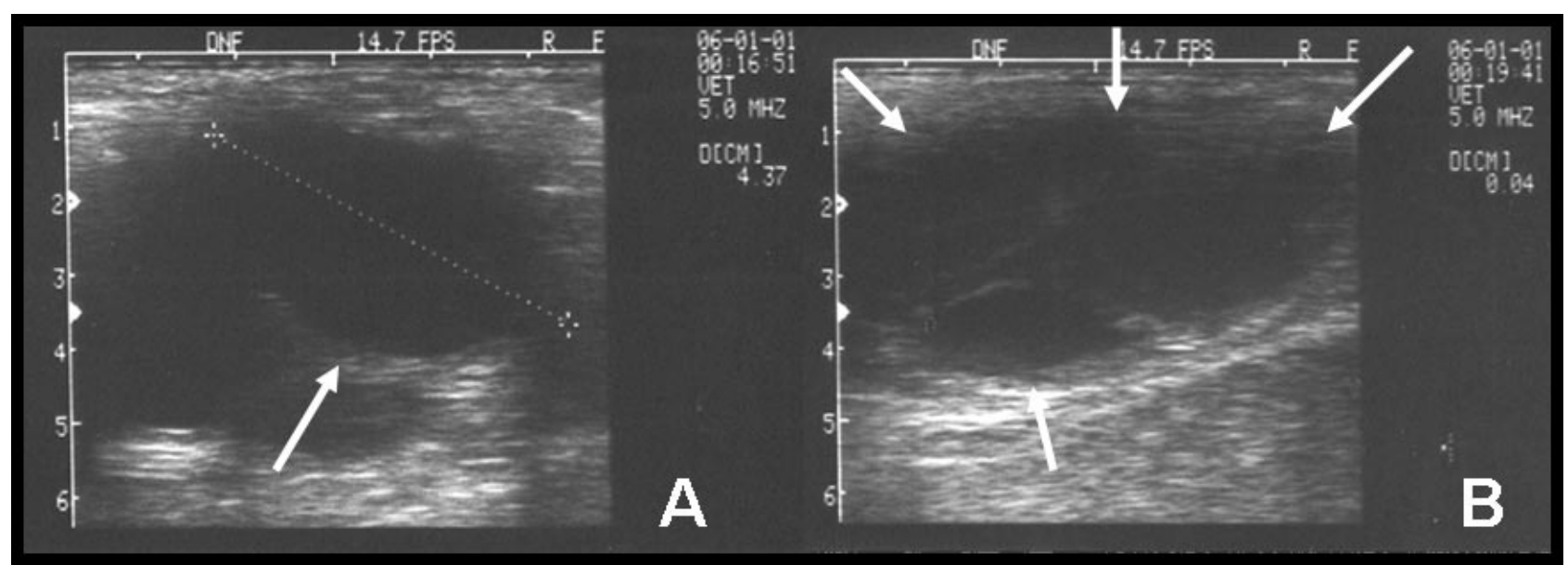

Figura 4. Imagem ultrassonográfica do ovário direito. Folículo ovariano com $43 \mathrm{~mm}$ - seta (A). Vista de quatro folículos no ovário direito - setas (B).

(17500pg/ml), e comportamento masculinizado além de presença de pêlos longos na região da cabeça e engrossamento do pescoço.

A persistência de anestro e a masculinização, sinais clínicos do animal descrito neste relato, são decorrentes da atividade hormonal presente em muitos tumores de cordão sexual, como o tecoma [2].

O animal foi reavaliado após um ano do procedimento cirúrgico. Na dosagem sérica hormonal foi encontrado níveis fisiológicos de progesterona e testosterona. Através de exame ultrassonográfico transretal foi verificada a presença de folículos ovaria- nos (Figura 4 A e B), o que evidencia o retorno da égua à atividade reprodutiva. Tais aspectos permitem concluir que a atividade reprodutiva só foi possível de ser retomada devido à remoção do tecoma presente no ovário direito, que agia como inibidor da atividade do ovário direito.

\section{NOTAS INFORMATIVAS}

${ }^{1}$ Catgut cromado 3 - Suturbras Indústrias e Comércio Ltda, Penha, 129, São Paulo, SP.

${ }^{2}$ Surgisorbpoint ${ }^{\circledR}$ - Point suture - rua Moacir, 435, Fortaleza, CE.

${ }^{3}$ Technofio® - Ace Ind. e Com, rua 07, 46 Goiânia, GO.

\section{REFERÊNCIAS}

1 Frederico L.M., Gerard M.P., Pinto C.R.F. \& Gradil C.M. 2007. Bilateral occurrence of granulosa-theca cell tumors in an Arabian mare. The Canadian Veterinary Journal. 5:502-505.

2 MacLachlan N.J. \& Kennedy P.C. 2002. Tumors of the ovary. In: Meutne D.J. (ed.). Tumors in domestic animals. 4.ed. Ames: A Blackwell Publishing Company, pp. 547-557.

3 McCue M. P. 1992. Equine granulosa cell tumors. In: Proceedings of the 38 th annual convention of the American Association of Equine Practitioners, Orlando - Florida.

4 McIlwraight W.C. \& Robertson J.T. 1998. Surgery of the urogenital system. McIlwraith \& Turner's equine surgery: advanced techniques. Baltimore: Williams \& Wilkins, v. 2. pp. 371-381.

5 Moll D.H. \& Slone D.E. 1999. Surgery of the ovaries. In: Wolfe D.F. \& Moll D.H. (Eds.) Large animal urogenital surgery. Baltimore: Williams \& Wilkins, pp. 137-146.

6 Moll D. H., Slone D.E., Juzwiak J.S. \& Garrett P.D. 1987. Diagonal paramedian approach for removal of ovarian tumors in the mare. Veterinary Surgery. 6:456-458.

7 Nie G.J. \& Momont H. 1992. Ovarian mass in three mares with regular estrous cycles. Journal of the American Veterinary Medical Association. 201:1043-1044.

8 Raoofi A., Mardjanmehr S.H., Masoudifard M., Adibhashemi F. \& Asadian P. 2006. Tecoma in a Mare: Case Report. Journal of Equine Veterinary Science. 12:588-591.

9 Sedrish S.A., MaClure J.R., Pinto C., Oliver J. \& Burba D.J. 1997. Ovarian torsion associated with granulosa-theca cell tumor in a mare. Journal of the American Veterinary Medical Association. 211:1152-1154. 
Nóbrega F.S., Gianotti G.C., Beck C.A.C., Alievi M.M.,Alice G., Arruda N.S., Rocio T.F., Gonzalez P.C. \& Ferreira M.P. Tecoma em uma égua.

10 Tecoma do ovário, 2007. Site didático de Anatomia Patológica, Neuropatologia e Neuroimagem. Disponível em: <http://anatpat.unicamp.br>. Acessado em 10/2007.

11 Watson E.D. 1998. Reproduction. In: Mair T., Love S., Schumacher J. \& Watson E. (Eds.). Equine Medicine, Surgery and Reproduction. London: WB Saunders, pp.278-309.

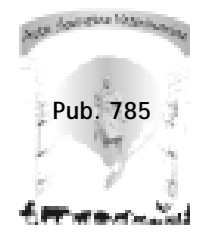

